\title{
Avaliação da susceptibilidade à corrosão de um aço inoxidável AISI 316L submetido à simulação térmica com o uso da Gleeble
}

\section{Assessment of susceptibility to corrosion of AISI $316 \mathrm{~L}$ stainless steel sub- mitted to thermal simulation with the use of Gleeble}

\author{
Thiago Aguiar Santos ${ }^{1}$, Renato Conde dos Santos ${ }^{1}$ \\ Waldemir dos Passos Martins ${ }^{1}$, Carmem Célia Francisco do Nascimento ${ }^{1}$ \\ ${ }^{1}$ Instituto Federal de Educação, Ciência e Tecnologia do Maranhão - IFMA - DMM/PPGEM - CEP: 65030-005, São \\ Luís, Maranhão, Brasil. \\ e-mail: thiago.aguiar@acad.ifma.edu.br, renato-c.s@hotmail.com,waldemir@ifma.edu.br, carmenfn@ifma.edu.br
}

\begin{abstract}
RESUMO
Este trabalho teve como finalidade avaliar a influência do tamanho médio dos grãos na susceptibilidade à corrosão do aço inoxidável austenítico AISI 316L, cujo material é bastante utilizado em juntas soldadas, em temperatura ambiente e em baixíssimas temperaturas (condições criogênicas) por apresentar excelente resistência à corrosão e boa ductilidade. Para tanto, amostras foram simuladas termicamente em uma Gleeble 3800 nas temperaturas de $900{ }^{\circ} \mathrm{C}$ e $1200{ }^{\circ} \mathrm{C}$ sob o tempo de permanência de $0,5,20$ e 100 segundos, controlando a taxa de resfriamento para em torno de $20^{\circ} \mathrm{C} / \mathrm{s}$ e sendo em seguida submetidas à análise de metalografia e de corrosão por técnicas eletroquímicas de polarização linear, usando uma solução de 3,5\% de cloreto de sódio $(\mathrm{NaCl})$. Além disso, foram realizados ensaios por análise de Raios-X nas amostras de maior e menor susceptibilidade à corrosão para verificação microestrutural. Os resultados mostraram que as amostras submetidas a $1200{ }^{\circ} \mathrm{C}$ apresentaram um aumento no tamanho médio dos grãos em relação às amostras de 900 ${ }^{\circ} \mathrm{C}$, tendo uma menor susceptibilidade à corrosão, exceto para a condição de $1200{ }^{\circ} \mathrm{C}$ a $100 \mathrm{~s}$. Entretanto nas amostras com $1200{ }^{\circ} \mathrm{C}$ a $100 \mathrm{~s}$ foram constatados carbonetos por análise de Raios-x e por fim, foi observado o fenômeno de corrosão por pite em todas as amostras.
\end{abstract}

Palavras-chave: AISI 316L, Corrosão, Tamanho médio de grão, Simulação térmica, Gleeble.

\begin{abstract}
The purpose of this work was to evaluate the influence of the average grain size on the corrosion susceptibility of AISI 316L austenitic stainless steel, which is widely used in welded joints, at room temperature and at very low temperatures (cryogenic conditions) because it has excellent corrosion resistance and good ductility. For this, samples were thermally simulated on a Gleeble 3800 at temperatures of $900^{\circ} \mathrm{C}$ and $1200^{\circ} \mathrm{C}$ under the residence time of $0,5,20$ and 100 seconds, controlling the cooling rate to around $20^{\circ} \mathrm{C} / \mathrm{s}$ followed by metallography and corrosion analysis using linear polarization electrochemical techniques using a solution of $3,5 \%$ sodium chloride $(\mathrm{NaCl})$. In addition, tests were performed by $\mathrm{x}$-ray analysis on samples of greater and lesser susceptibility to corrosion for microstructural verification. The results showed that the samples submitted to $1200^{\circ} \mathrm{C}$ presented a bigger increase in the average grain size in relation to the samples of $900^{\circ} \mathrm{C}$, having a lower susceptibility to corrosion, except for the condition of $1200^{\circ} \mathrm{C}$ to $100 \mathrm{~s}$. However in the samples with $1200^{\circ} \mathrm{C}$ to 100 s, carbides were detected by X-ray analysis and finally, the corrosion phenomena were observed by pitting in all samples.
\end{abstract}

Keywords: AISI 316L, Corrosion, Average grain size, Thermal simulation, Gleeble.

\section{INTRODUÇÃO}

O aço inoxidável austenítico é uma liga composta principalmente por cromo e níquel, elementos que tornam este tipo de material resistente à corrosão devido à formação de uma fina camada composta por óxido de cromo $\left(\mathrm{Cr}_{2} \mathrm{O}_{3}\right)$ [1]. Quanto maior a adição de cromo, mais estável é a película passiva. Contudo o excesso deste elemento pode afetar as propriedades mecânicas e de soldagem, sendo necessária a adição de elementos de liga para melhorar a resistência à corrosão. 
Na escala industrial, o aço inoxidável austenítico é bastante utilizado em superfícies expostas à atmosfera, imersão em água doce e salgada, além de ser utilizada em equipamentos de processos tendo seu uso limitado a meios que levam a quebra da película passiva [2]. Segundo Wolynec [3]], os fenômenos de corrosão em meios aquosos ocorre com maior frequência, onde o processo eletroquímico é característico para tal mecanismo.

De acordo com Nunes [2]], a ação eletroquímica ocorre na natureza associando uma célula de corrosão à formação de potenciais em uma solução diluída com transferência de íons do material para a solução. Dessa forma, a maioria das reações ocorrem na superfície metálica através da indução de passagem da corrente elétrica. De acordo com Berton [4] os principais tipos de corrosão que podem ocorrer nos aços inoxidáveis são: corrosão por pite, por frestas, intergranular, sob tensão e por hidrogênio.

Adicionado a isso, quando os aços inoxidáveis austeníticos são submetidos a intervalo de temperaturas entre $450^{\circ} \mathrm{C}$ e $850^{\circ} \mathrm{C}$ por um determinado tempo, ocorre a sensitização com precipitação de carbonetos de cromo $\left(\mathrm{Cr}_{23} \mathrm{C}_{6}\right)$ em seus contornos de grão, comprometendo sua resistência à corrosão [5]. Silva et al. [6] constatou que realizando tratamento térmico no aço inoxidável austenítico AISI 316L imersos em petróleo aquecido a $200^{\circ} \mathrm{C}$ e $300^{\circ} \mathrm{C}$, houve uma diferença na taxa de corrosão nos dois casos evidenciando que a degradação do material se deu de forma mais acentuada para o tratamento a $300^{\circ} \mathrm{C}$.

De acordo com Kianersi et al. [7], Özyürek [8], Kocabekir et al. [9] e Zheng et al. (2010) [20], o aumento da quantidade de calor em um processo de soldagem causa um ligeiro aumento no tamanho médio dos microconstituintes do cordão de solda e da zona afetada pelo calor (ZAC) dos aços inoxidáveis austeníticos.

Pesquisas realizadas por Li et al. [10] com o aço AISI 316L mostraram que o aumento no tamanho médio dos grãos torna o material mais resistente à corrosão intergranular, com formação de carbonetos de cromo nos contornos dos grãos. Williams e Barbaro [11] também observaram que a corrosão intergranular e localizada (pite) de um aço inoxidável não estabilizado contendo $12 \%$ de cromo foi influenciada pelo percentual, morfologia e distribuição dos microconstituintes, além do tamanho médio dos grãos, no qual para um menor tamanho médio dos grãos a corrosão era mais severa.

Estudo semelhante realizado por Chaturverdi e Jena [12], também observou que o aumento no tamanho médio dos grãos em temperaturas elevadas, ocasionou uma área maior do contorno de grão resultando maior formação de precipitados, como carboneto de cromo ao longo desses contornos, sucedendo uma zona enfraquecida e propícia à corrosão. Além disso, a susceptibilidade à corrosão dos aço inoxidáveis austeníticos está relacionada à precipitação desses carbonetos de cromo nos contornos dos grãos [13].

Para Mandziej [13] e Ramírez [17], os procedimentos de simulação física permitem estudar o comportamento dos materiais em condições muito perto ao processamento ou aplicações industriais reais. Parâmetros do processo, tais como temperatura, quantidade de tensão, taxa de deformação e outros gradientes podem ser adequadamente reproduzidas e seus valores registrados com precisão. Além disso, por meio de simulação física uma grande variedade de microestruturas e propriedades mecânicas associadas podem ser obtidas, como a zona afetada pelo calor (ZTA), podendo alcançar temperaturas que possibilitam a simulação do tamanho médio dos grãos desta região. Os dados do comportamento de materiais adquiridos a partir de experiências físicas de simulação podem ainda ser utilizados em modelagem e controle dos processos de fabricação industrial [21].

Alguns trabalhos como o realizado por Amaral et al.[26] e por Silva [27], evidenciaram a simulação térmica como um procedimento induzido capaz de representar com relativa proximidade as condições obtidas em processamento real. Entretanto, associar o aumento do tamanho médio dos grãos obtidos por ciclos térmicos simulados à susceptibilidade à corrosão em determinado meio é um desafio que possui poucas referências. Desta forma, o objetivo deste trabalho é avaliar a influência do tamanho médio dos grãos na simulação térmica de duas temperaturas distintas $900^{\circ} \mathrm{C}$ e $1200^{\circ} \mathrm{C}$ com tempo de permanência de $0,5,20$ e $100 \mathrm{~s}$ na susceptibilidade à corrosão do aço inoxidável austenítico AISI 316L.

\section{MATERIAIS E MÉTODOS}

As etapas para avaliação da susceptibilidade à corrosão do aço inoxidável 316L submetido a uma simulação térmica foram divididas em cinco partes. Parte (I): Preparação dos corpos de prova. Parte (II): Simulação térmica. Parte (III): Ensaio de corrosão potenciodinâmica. Parte (IV): Análise da microestrutura por MO e DRX.

\subsection{Preparação dos corpos de prova}

Foi escolhido o aço inoxidável austenítico 316L com a composição química apresentada na Tabela 1: 
Tabela 1: Composição química do AISI 316L (\% em peso).

\begin{tabular}{c|c|c|c|c|c|c|c|c|c|c}
\hline AISI & $\mathbf{C}$ & $\mathbf{M n}$ & $\mathbf{S i}$ & $\mathbf{P}$ & $\mathbf{S}$ & $\mathbf{C r}$ & $\mathbf{N i}$ & Mo & $\mathbf{C o}$ & $\mathbf{C u}$ \\
\hline 316L & 0,023 & 1,53 & 0,42 & 0,039 & 0,025 & 16,54 & 10,02 & 2,05 & 0,150 & 0,6 \\
\hline
\end{tabular}

Os corpos de prova submetidos a simulação térmica com uso da Gleeble 3800 possuem $84 \mathrm{~mm}$ de comprimento por $10 \mathrm{~mm}$ de diâmetro. A região central das amostras foi reduzida a $5 \mathrm{~mm}$ de diâmetro por 5 mm de comprimento para os ensaios térmicos (Figura 1).

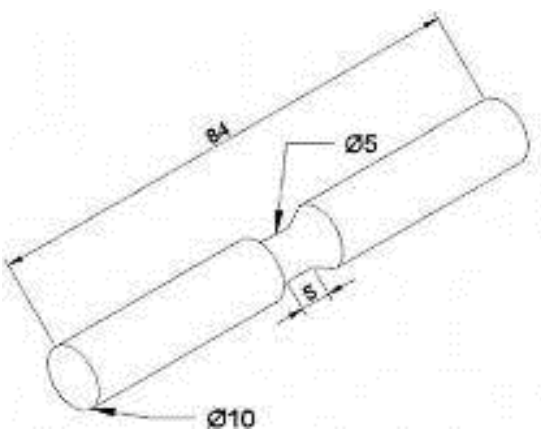

Figura 1: Preparação do corpo de prova a ser submetido ao simulador térmico.

\subsection{Simulação Térmica}

A simulação termodinâmica foi realizada em um simulador Gleeble 3800. Os corpos de prova foram aquecidos em duas temperaturas distintas, $900^{\circ} \mathrm{C}$ e $1200^{\circ} \mathrm{C}$ com uma taxa de $500{ }^{\circ} \mathrm{C} / \mathrm{s}$, permanecendo nestas temperaturas por $0,5,20$ e $100 \mathrm{~s}$, sendo em seguida resfriadas com taxa de $20^{\circ} \mathrm{C} / \mathrm{s}$. Todo o procedimento de simulação foi realizado em câmara à vácuo para evitar a oxidação. Foram realizados 5 ensaios para cada condição com o objetivo de ter repetitividade no tamanho médio dos grãos para o estudo de corrosão, afim de garantir uma boa confiabilidade nos resultados. Uma ilustração do esquema pode ser verificado na Figura 2.

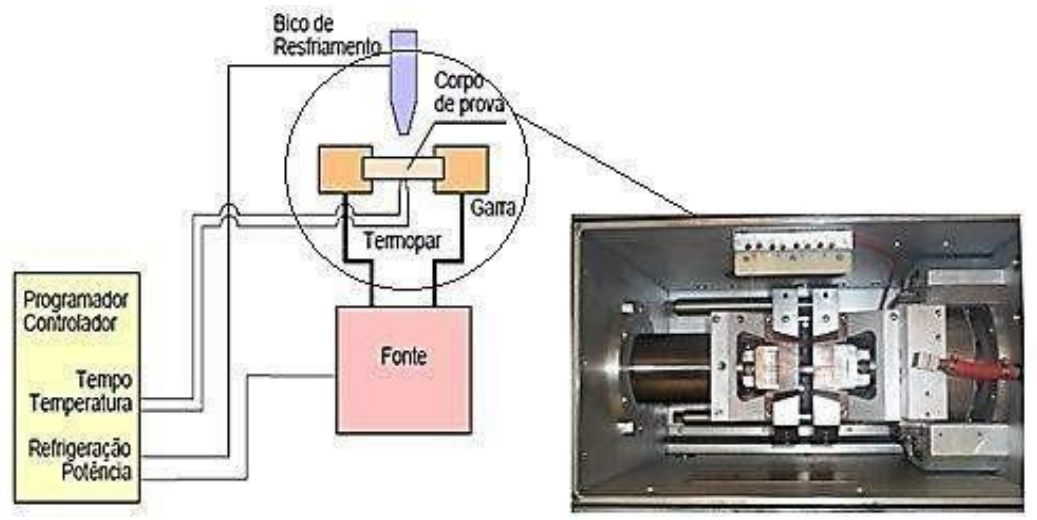

Figura 2: Representação do funcionamento do simulador termodinâmico Gleeble 3800.

\subsection{Ensaio de corrosão potenciodinâmica}

Afim de analisar a susceptibilidade à corrosão das amostras, ensaios de polarização linear foram realizados numa célula eletroquímica equipada com um sistema de três eletrodos: eletrodo de referência ECS Calomelano Saturado (B), eletrodo de trabalho (A) e o contra-eletrodo de platina (C) conectados à um potenciostato modelo - PGSTAT 302N - AutoLab, usando uma solução aquosa contendo $100 \mathrm{~mL}$ de $\mathrm{NaCl}$ (cloreto de sódio) a 3,5\% (Figura 3). Para o ensaio, usou-se uma taxa de varredura a $1 \mathrm{mV} / \mathrm{s}$ e o potencial com varredura de $-1,2$ a 0,6 Volts, de onde foram obtidos o potencial de circuito aberto (OCP), potencial de corrosão (Epotencial) e o potencial de pite (Epite). Além disso, para uniformidade entre as amostras durante a realização do ensaio, a extensão da área das amostras foram fixadas em 25 mm2. 


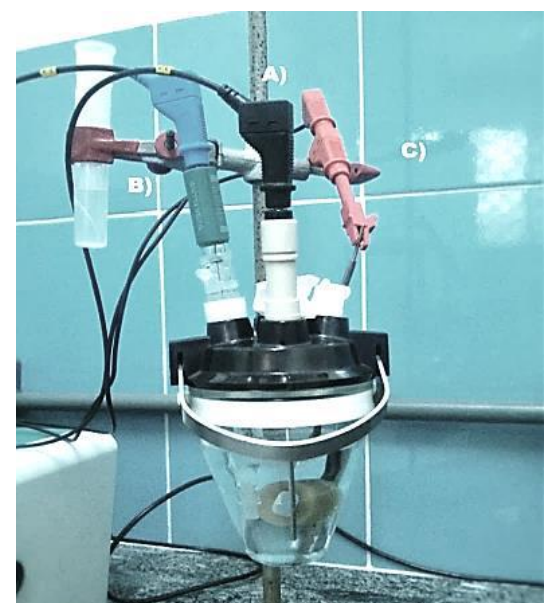

Figura 3: Ilustração dos três eletrodos: (a) Eletrodo de Platina; (b) Eletrodo de Referência de Calomelano Saturado; (c) Eletrodo de Trabalho

\subsection{Análise da microestrutura por MO e DRX}

Após os ensaios de simulação térmica realizados na Gleeble 3800, cinco amostras de cada condição foram retiradas da parte central dos corpos de prova (corte transversal), sendo em seguida embutidas e lixadas com lixas de granulometria de \#180 a \#1200 e polidas com alumina de $1 \mu \mathrm{m}$ e $0,3 \mu \mathrm{m}$. Além disso, uma amostra neutra também foi preparada para fins de comparação. Em seguida, as amostras foram atacadas eletroliticamente com uma solução de ácido nítrico $\left(\mathrm{HNO}_{3}\right)$ a $40 \%$, usando uma corrente de 1,5 Amperes por 15 segundos, segundo a norma ASTM E 407 - 99 [23]. Posteriormente, foi realizado análise por microscopia óptica onde foram calculados os tamanhos médios dos grãos com auxílio do programa Quantikov [24], versão 11.7/2015, desenvolvido com ferramentas baseado na norma ASTM E112-13 [25] que utiliza como parâmetro o método do intercepto linear. Uma nova análise por MO foi realizada após os ensaios de corrosão potenciodinâmica, para verificação da morfologia da corrosão.

A técnica de difração de raios-x (DRX) foi utilizada para identificar as variações microestruturais. Para tanto, foram escolhidas as amostras com menor susceptibilidade na condição de $900{ }^{\circ} \mathrm{C}$ e a de maior susceptibilidade à corrosão na condição de $1200{ }^{\circ} \mathrm{C}$ tendo em vista que a possibilidade da presença de carbonetos ou fases presentes no material e identificáveis pelo DRX, influenciam diretamente no filme passivo formado principalmente nos aços inoxidáveis $[13,18]$.

\section{RESULTADOS E DISCUSSÕES}

A partir da simulação térmica realizada na Gleeble, foi possível obter os gráficos dos ciclos térmicos nas temperaturas de 900 e $1200^{\circ} \mathrm{C}$ (Figuras 4 e 5). A variação do tempo de permanência na temperatura de pico pode ser observada na Figura 3 para $900^{\circ} \mathrm{C}$, com respectivamente 0 segundos, 5 segundos, 20 segundos e 100 segundos, sendo posteriormente resfriados à temperatura ambiente com aproximadamente $20^{\circ} \mathrm{C} / \mathrm{s}$. De forma semelhante, o corpo de prova submetido à temperatura de $1200^{\circ} \mathrm{C}$ com variação no tempo de permanência na temperatura de pico de 0 segundos, 5 segundos, 20 segundos e 100 segundos é observado na Figura 4, sendo também resfriados à temperatura ambiente $\left(\approx 20^{\circ} \mathrm{C} / \mathrm{s}\right)$. Dessa forma, os parâmetros de soldagem podem ser reproduzidos para análise microestrutural do material ao fim dos processos, considerando as tensões residuais naturalmente impostas pelo ciclo térmico de soldagem com a finalidade de simular o tamanho médio dos grãos da região em estudo [13, 14, 17, 21]. É importante ressaltar que a escolha das temperaturas se deve apenas como método comparativo para analisar o tamanho médio dos grãos formados pelo acréscimo de temperatura, do tempo de permanência na devida temperatura e da susceptibilidade à corrosão nestas condições estudadas.

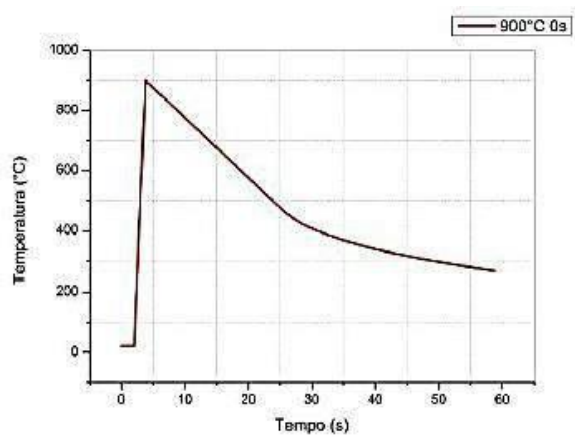

(a)

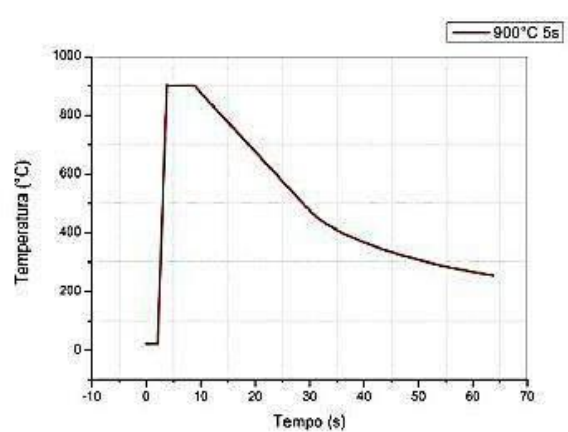

(b) 


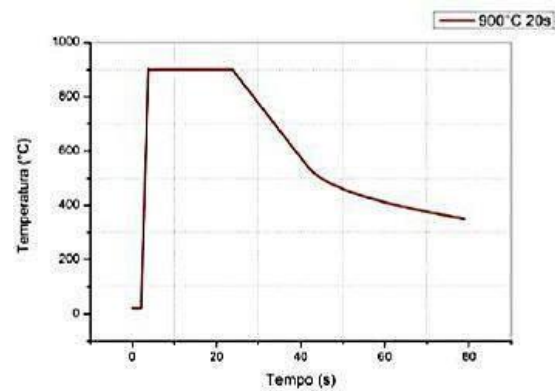

(c)

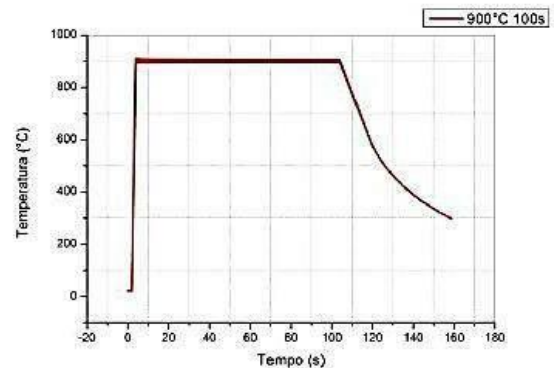

(d)

Figura 4: Representação dos ciclos térmicos com a temperatura máxima de $900^{\circ} \mathrm{C}$ : (a) $900^{\circ} \mathrm{C}$ a 0 segundo; (b) $900^{\circ} \mathrm{C}$ a 5 segundos; (c) $900^{\circ} \mathrm{C}$ a 20 segundos e; (d) $900^{\circ} \mathrm{C}$ a 100 segundos.

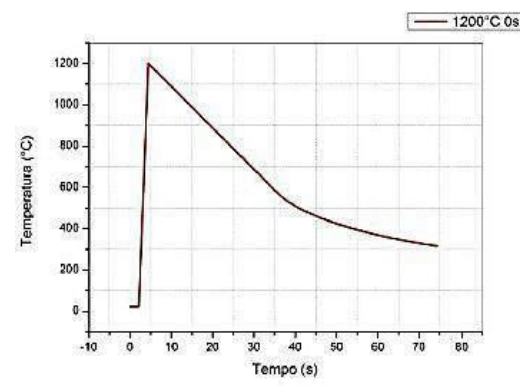

(a)

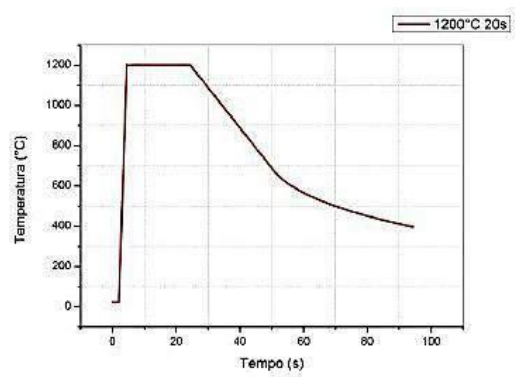

(c)

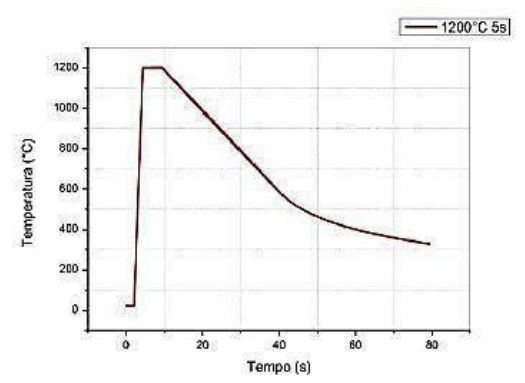

(b)

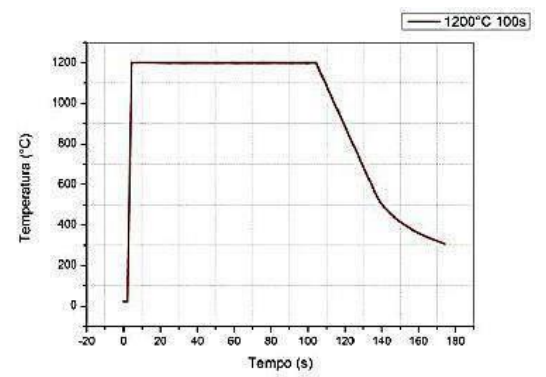

(d)

Figura 5: Representação dos ciclos térmicos com a temperatura máxima de $1200^{\circ} \mathrm{C}$ : (a) $1200^{\circ} \mathrm{C}$ a 0 segundo; (b) $1200^{\circ} \mathrm{C}$ a 5 segundos; (c) $1200^{\circ} \mathrm{C}$ a 20 segundos e; (d) $1200^{\circ} \mathrm{C}$ a 100 segundos.

\subsection{Cálculo do Tamanho Médio dos Grãos}

A partir dos resultados da simulação dos corpos de prova do aço inoxidável AISI 316L, foram realizadas micrografias das amostras para determinar o tamanho médio dos grãos mostrados nas Figuras de 6 a 8 . Através destas micrografias foi possível utilizar um analisador de imagem para medir o tamanho médio dos grãos, como pode ser observado na Tabela 2.

Observa-se que o maior e o menor tamanho médio dos grãos foram obtidos nas condições de $1200^{\circ} \mathrm{C}$ com tempo de permanência de 100 segundos e $900^{\circ} \mathrm{C}$ com 0 segundo, respectivamente, sendo atribuído às reações de recristalização das amostras na condição de temperatura mais elevada $\left(1200^{\circ} \mathrm{C}\right)$ e do pouco tempo de permanência na temperatura de $900^{\circ} \mathrm{C}$, não dando tempo suficiente para que ocorresse a restauração de forma proressiva com a elevação da temperatura. O aço austenítico normalmente é recristalizado na faixa de temperatura de 1000 à $1100^{\circ} \mathrm{C}$, seguido do processo de crescimento dos grãos que depende da temperatura, do tempo e da composição química do material [28]. Ainda sim, o tamanho médio dos grãos dessas condições são maiores quando comparadas à amostra neutra [7, 8, 9, 18, 19]. 


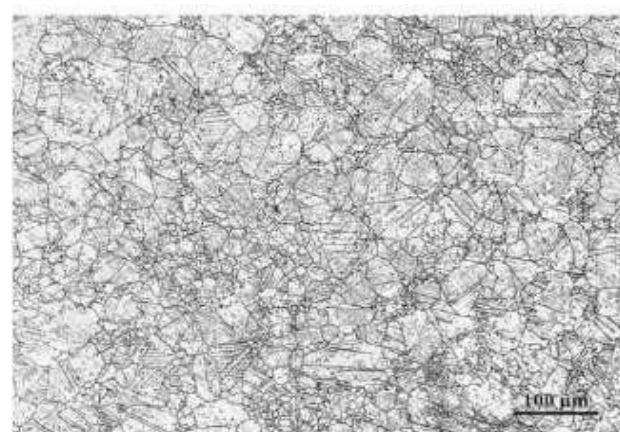

(a)

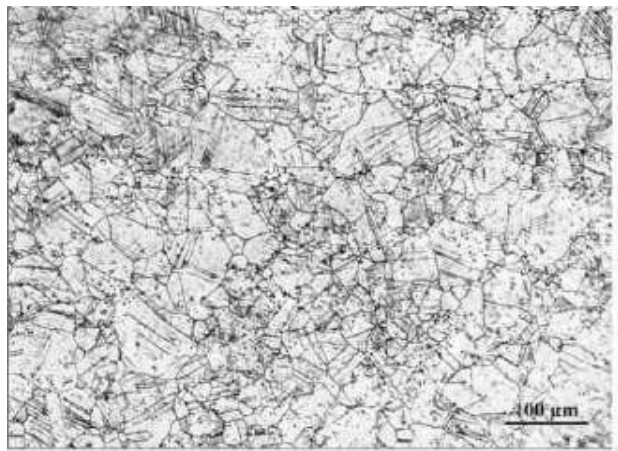

(c)

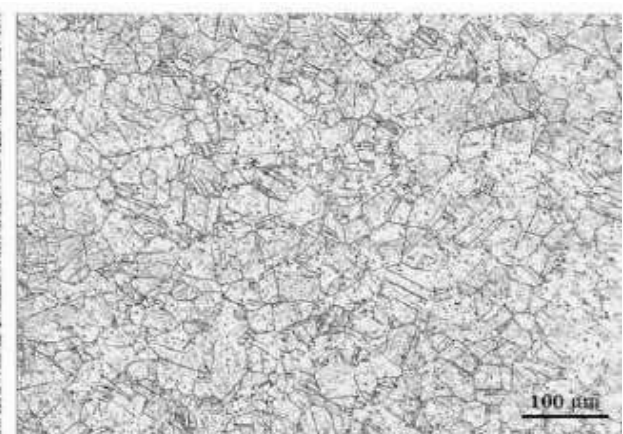

(b)

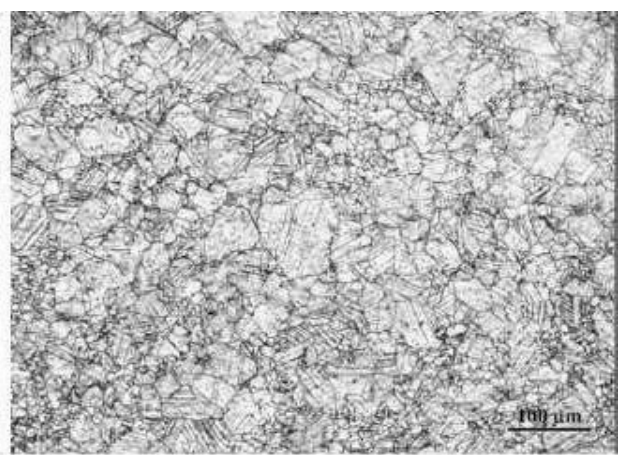

(d)

Figura 6: Micrografia das amostras à $900^{\circ} \mathrm{C}$ : (a) 0 segundos; (b) 5 segundos; (c) 20 segundos e; (d) 100 segundos.

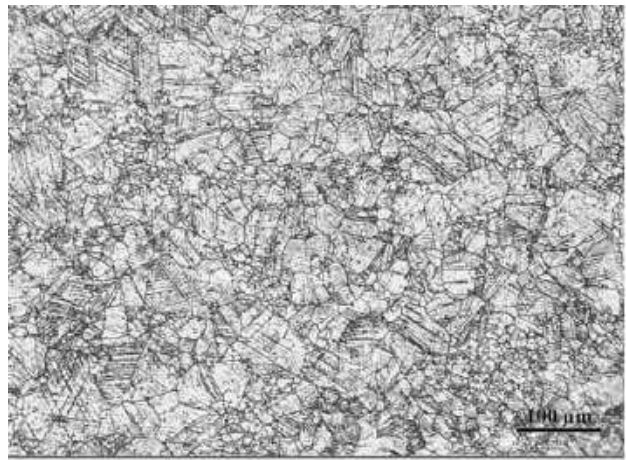

(a)

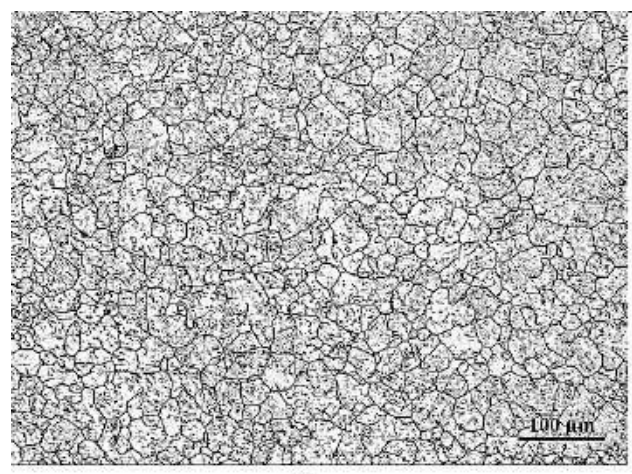

(c)

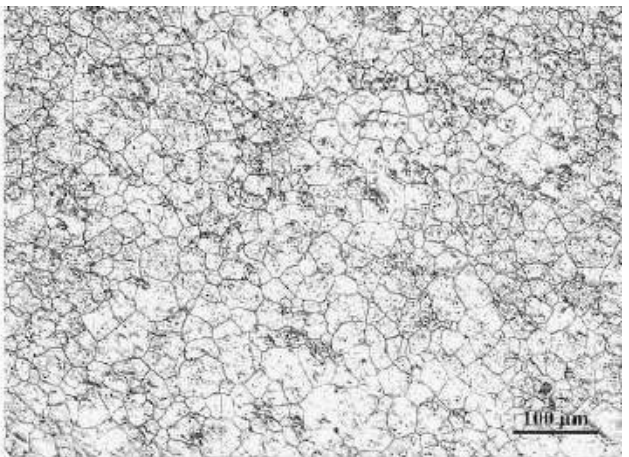

(b)

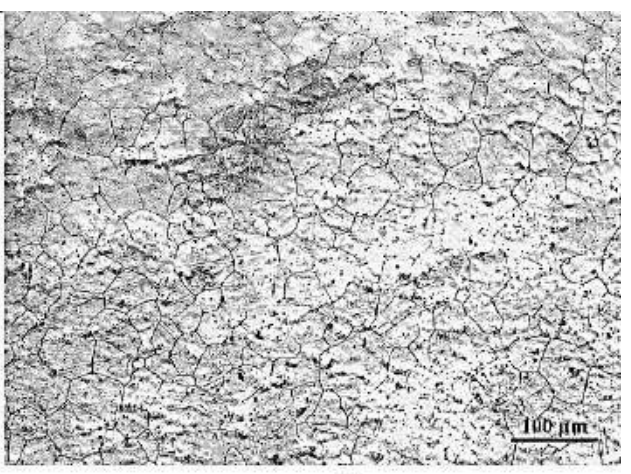

(d)

Figura 7: Micrografia das amostras à $1200^{\circ} \mathrm{C}$ : (a) 0 segundos; (b) 5 segundos; (c) 20 segundos e; (d) 100 segundos. 


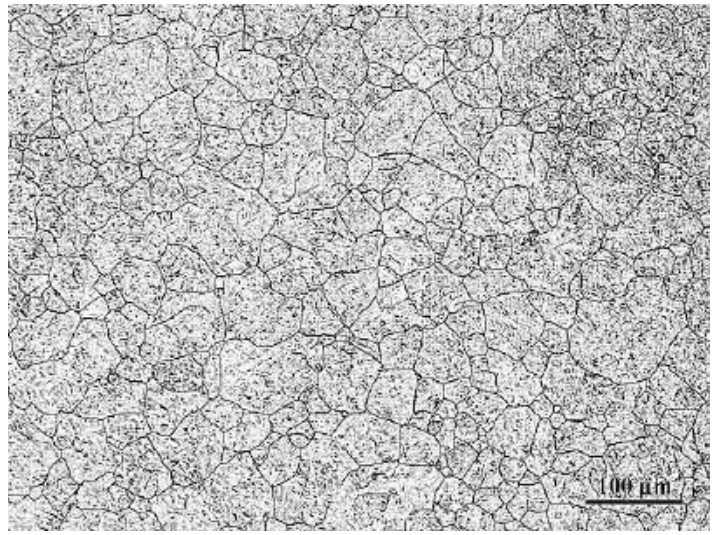

Figura 8: Micrografia da amostra neutra (como obtida de fábrica)

Tabela 2: Tamanho médio dos grãos para cada condição térmica estudada.

\begin{tabular}{c|c|c}
\hline Amostras & $\begin{array}{c}\text { Tamanho médio dos grãos } \\
(\boldsymbol{\mu m})\end{array}$ & Erro médio (S) \\
\hline Neutra & 28,56 & 0,023 \\
$900^{\circ} \mathrm{C} / 0 \mathrm{~s}$ & 32,16 & 0,035 \\
$900^{\circ} \mathrm{C} / 5 \mathrm{~s}$ & 35,54 & 0,041 \\
$900^{\circ} \mathrm{C} / 20 \mathrm{~s}$ & 38,58 & 0,063 \\
$900^{\circ} \mathrm{C} / 100 \mathrm{~s}$ & 40,21 & 0,066 \\
$1200^{\circ} \mathrm{C} / 0 \mathrm{~s}$ & 47,14 & 0,075 \\
$1200^{\circ} \mathrm{C} / 5 \mathrm{~s}$ & 49,36 & 0,069 \\
$1200^{\circ} \mathrm{C} / 20 \mathrm{~s}$ & 52,39 & 0,082 \\
$1200^{\circ} \mathrm{C} / 100 \mathrm{~s}$ & 54,11 & 0,092 \\
\hline
\end{tabular}

\subsection{Susceptibilidade à corrosão das amostras simuladas à $900^{\circ} \mathrm{C}$ e $1200^{\circ} \mathrm{C}$}

Após calcular o tamanho médio dos grãos, foi utilizado um potenciostato para auxiliar os ensaios de corrosão eletroquímica por polarização potenciodinâmica, onde se obteve o gráfico formado pelo potencial x densidade de corrente (Figura 9), tanto para as condições de $900{ }^{\circ} \mathrm{C}$ quanto para as condições de $1200^{\circ} \mathrm{C}$. Utilizando o método de extrapolação de Tafel para obtenção dos valores dos potenciais de corrosão e pite, e das densidades de corrosão e pite expressos na Tabela 3, observa-se que ao comparar as condições de $900{ }^{\circ} \mathrm{C}$ e $1200{ }^{\circ} \mathrm{C}$, o aumento no tamanho médio dos grãos influenciou no sentido de aumentar o potencial de corrosão e consequentemente diminuir a susceptibilidade à corrosão das amostras simuladas, sendo que esse aumento de potencial ficou mais evidente na condição de $1200^{\circ} \mathrm{C}$ no tempo de permanência de 0 segundo ($0,68181 \mathrm{~V}$ e $5,2614 \mathrm{E}-7 \mathrm{~A} / \mathrm{cm}^{2}$ ), isso mostra que na temperatura de $1200^{\circ} \mathrm{C}$ com tamanho médio dos grãos maiores tem uma menor área de contorno de grão e consequentemente menor contato com o meio agressivo, aumentando a resistência à corrosão. Estudos realizados Li et al. (2013) [10], Li et al. (2011)[22] e Guo et al. (2016) [16] mostraram este comportamento.

Entretanto, na condição de $1200^{\circ} \mathrm{C}$ com tempo de permanência de 100 s $(-0,83977 \mathrm{~V}$ e $5,7468 \mathrm{E}-7$ $\mathrm{A} / \mathrm{cm}^{2}$ ) não foi observado uma menor susceptibilidade à corrosão, indicando que não houve uma boa homogeneização da microestrutura e/ou do tamanho médio dos grãos da amostra simulada, podendo estar atrelada também com a formação de carbonetos de cromo ou ferrita delta que ocasionam um aumento na susceptiblidade à corrosão do material em estudo[18]. Dentre as amostras simuladas à $900{ }^{\circ} \mathrm{C}$, foi observado que a condição com tempo de permanência de 20 segundos se obteve uma menor susceptibilidade à corrosão, sugerindo que o tempo de permanência na devida temperatura ocasionou uma boa homogeinização na microestrutura em análise. 


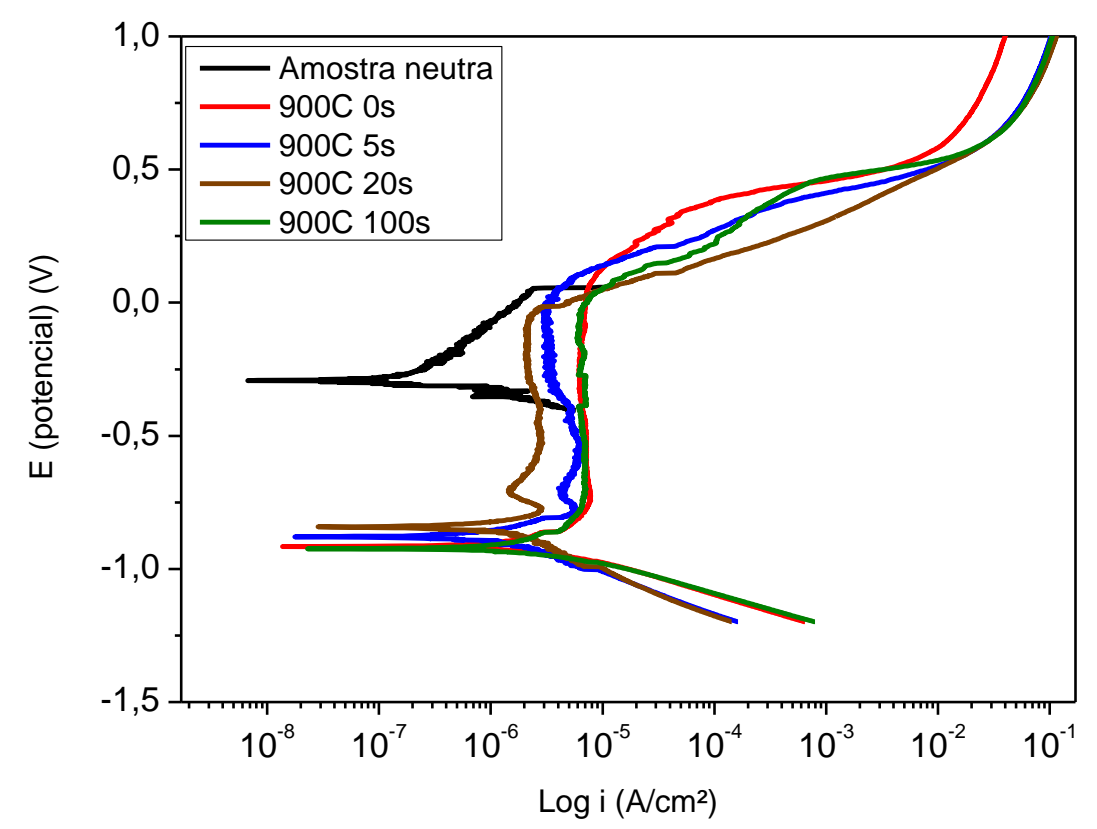

(a)

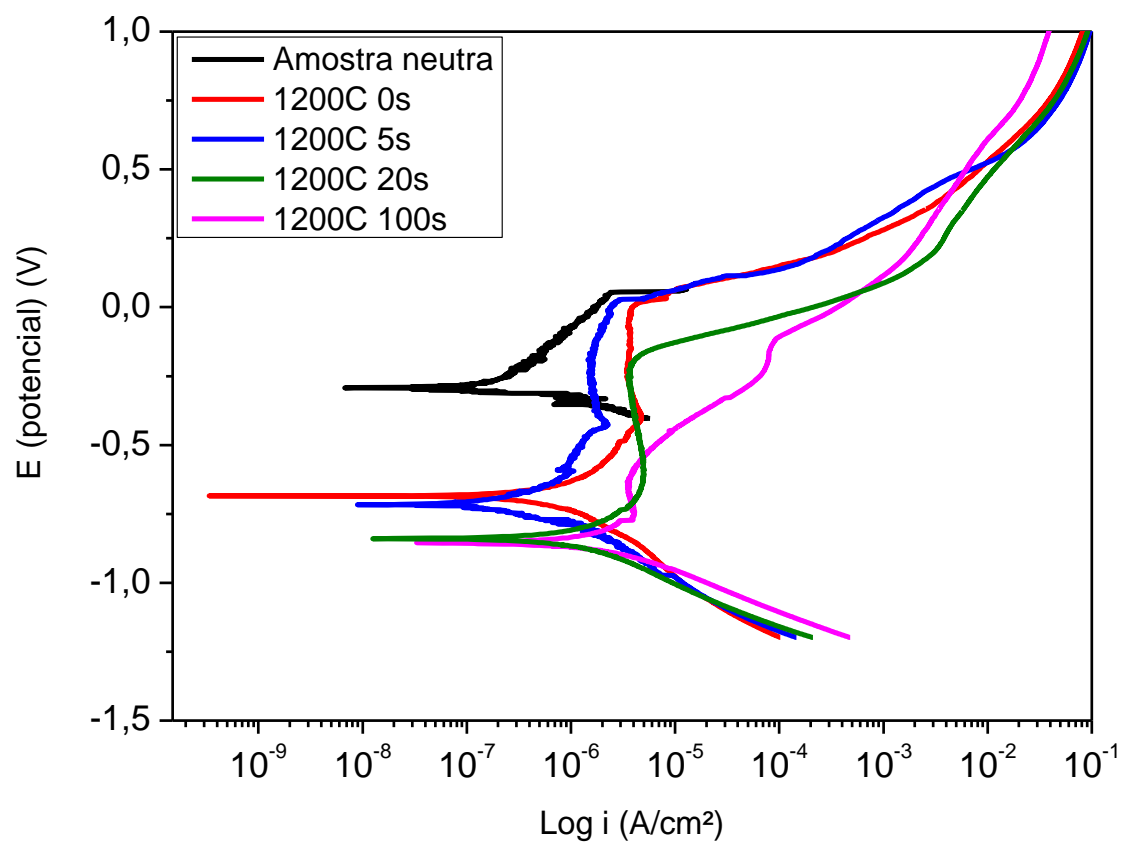

(b)

Figura 9: Gráfios obtidos pelos dados gerados no potenciostato durante o ensaio de corrosão potenciodinâmica das amostras neutra e as submetidas à: (a) $900^{\circ} \mathrm{C}$ e (b) $1200^{\circ} \mathrm{C}$. 
Tabela 3: Valores do potencial e corrente de corrosão das amostras simuladas

\begin{tabular}{|c|c|c|c|c|c|}
\hline Amostra & $\begin{array}{l}\text { Potencial de } \\
\text { Corrosão } \\
\text { (V) }\end{array}$ & $\begin{array}{l}\text { Densidade } \\
\text { de } \\
\text { Corrente } \\
(\log (\mathrm{i})) \\
\left(\mathrm{A} / \mathrm{cm}^{2}\right)\end{array}$ & $\begin{array}{l}\text { Potencial } \\
\text { de Pite } \\
\text { (V) }\end{array}$ & $\begin{array}{l}\text { Densidade de } \\
\text { Corrente do pite } \\
\qquad \begin{array}{c}(\log (i)) \\
\left(A / \mathrm{cm}^{2}\right)\end{array}\end{array}$ & $\begin{array}{c}\text { Tamanho } \\
\text { Médio de } \\
\text { Grão } \\
(\mu \mathrm{m})\end{array}$ \\
\hline Amostra Neutra & $-0,29$ & $3,82 \mathrm{E}-8$ & 0,05 & $2,47 \mathrm{E}-6$ & 28,56 \\
\hline $900^{\circ} \mathrm{C} / 0 \mathrm{~s}$ & $-0,91$ & $1,10 \mathrm{E}-6$ & 0,06 & $6,54 \mathrm{E}-6$ & 32,16 \\
\hline $900^{\circ} \mathrm{C} / 5 \mathrm{~s}$ & $-0,87$ & $3,15 \mathrm{E}-7$ & 0,05 & $3,09 \mathrm{E}-6$ & 35,54 \\
\hline $900^{\circ} \mathrm{C} / 20 \mathrm{~s}$ & $-0,84$ & $1,97 \mathrm{E}-7$ & $-0,04$ & $2,08 \mathrm{E}-6$ & 38,58 \\
\hline $900^{\circ} \mathrm{C} / 100 \mathrm{~s}$ & $-0,92$ & $1,24 \mathrm{E}-7$ & $-0,03$ & $5,87 \mathrm{E}-6$ & 40,21 \\
\hline $1200^{\circ} \mathrm{C} / 0 \mathrm{~s}$ & $-0,68$ & $5,26 \mathrm{E}-7$ & 0,004 & $3,53 \mathrm{E}-6$ & 47,14 \\
\hline $1200^{\circ} \mathrm{C} / 5 \mathrm{~s}$ & $-0,71$ & $1,40 \mathrm{E}-7$ & 0,03 & $2,77 \mathrm{E}-6$ & 49,36 \\
\hline $1200^{\circ} \mathrm{C} / 20 \mathrm{~s}$ & $-0,85$ & $5,56 \mathrm{E}-7$ & $-0,18$ & $3,38 \mathrm{E}-6$ & 52,39 \\
\hline $1200^{\circ} \mathrm{C} / 100 \mathrm{~s}$ & $-0,83$ & $5,74 \mathrm{E}-7$ & $-0,11$ & $9,07 \mathrm{E}-5$ & 54,11 \\
\hline
\end{tabular}

Na Figura 10 observa-se que houve corrosão por pite e que a variação no tamanho médio dos grãos influenciou na distribuição e o tamanho dos pites, onde para tempos de permanência maiores, as áreas formadas pelos pites são ligeiramento maiores em relação às amostras com tempo de permanência menor. Ainda analisando a Tabela 3, pode-se perceber que a condição de $1200{ }^{\circ} \mathrm{C}$ a 100 segundos e $900{ }^{\circ} \mathrm{C}$ a 20 segundos obtiveram os menores potenciais de pite, com - $0,18 \mathrm{~V}$ e $-0,04 \mathrm{~V}$ respectivamente, obtendo valores inferiores quando comparados com amostra neutra $(0,05 \mathrm{~V})$, o que está relacionado à variação do tamanho médio dos grãos $[7,8,9,19]$.

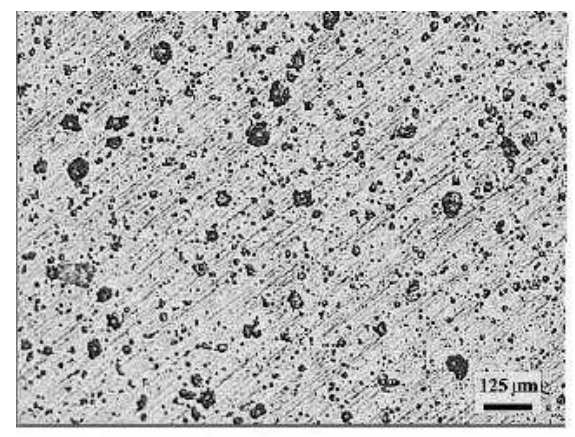

(a)

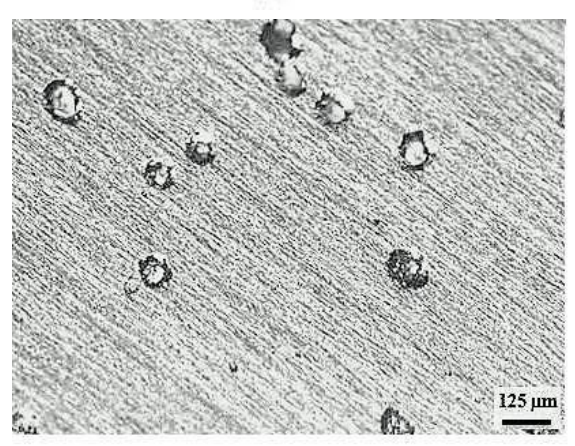

(c)

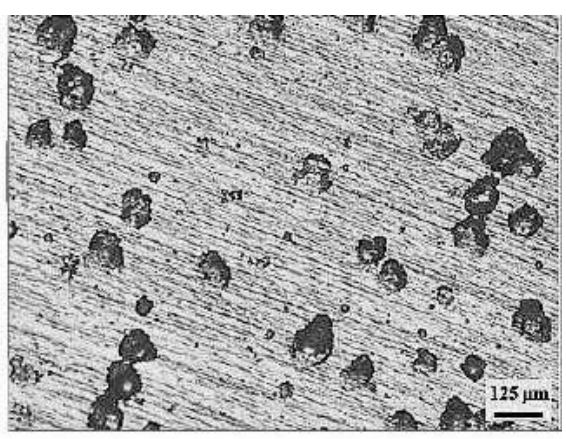

(b)

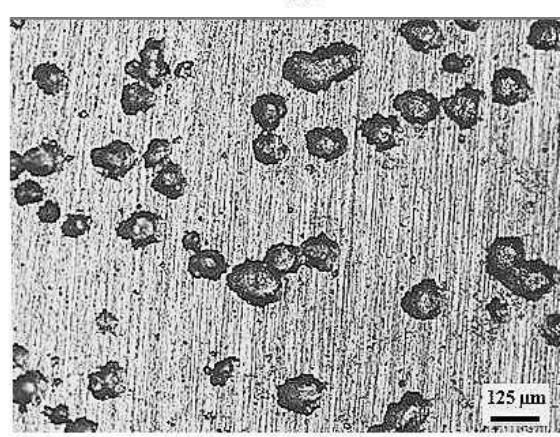

(d) 


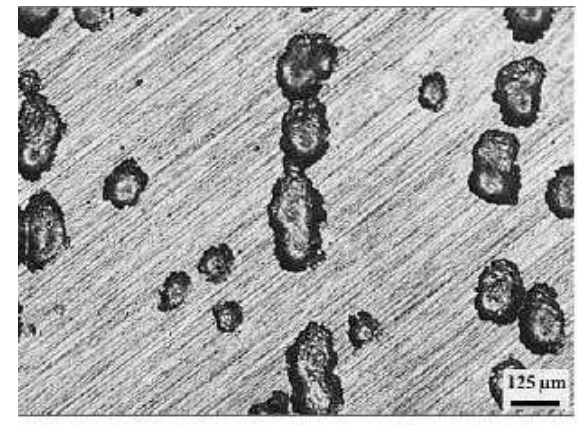

(e)

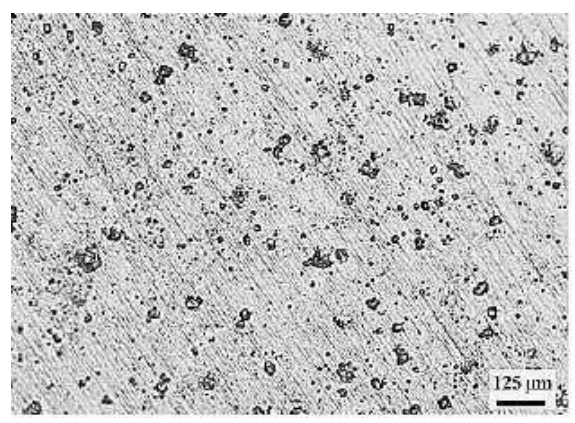

(g)

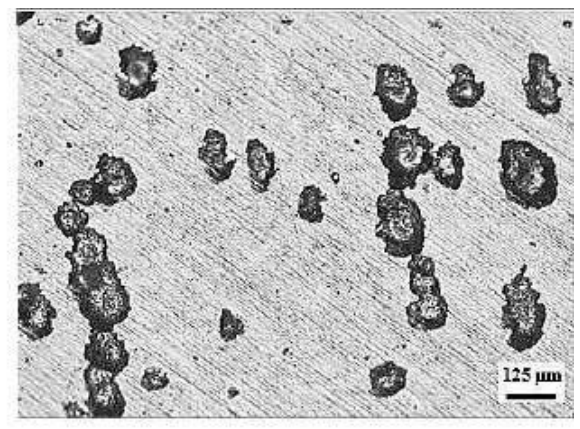

(f)

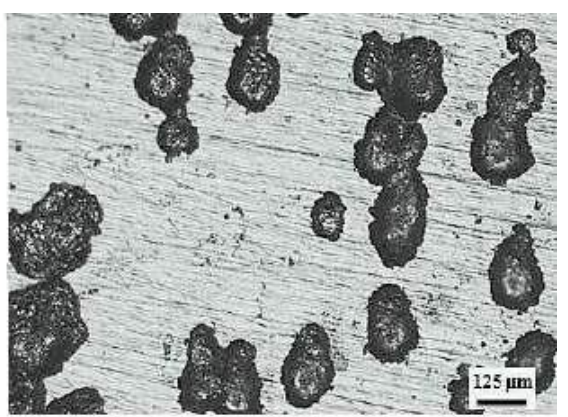

(h)

Figura 10: Micrografia após os ensaios de corrosão para: $900^{\circ} \mathrm{C}$ (a) $0 \mathrm{~s}$, (b) $5 \mathrm{~s}$, (c) $20 \mathrm{~s}$, (d) 100 e $1200^{\circ} \mathrm{C}$ (e) $0 \mathrm{~s}$, (f) $5 \mathrm{~s}$, (g) $20 \mathrm{~s}$, (h) $100 \mathrm{~s}$

\subsection{Análise Através de DRX}

Após o ensaio de corrosão eletroquímica, foi escolhida uma amostra de cada faixa de temperatura para realizar a análise através do DRX. Para tanto, dentre as amostras de $900^{\circ} \mathrm{C}$ escolheu-se a com tempo de permanência a $20 \mathrm{~s}$, por ela apresentar menor susceptibilidade à corrosão entre as condições de mesma temperatura, já para as amostras de $1200{ }^{\circ} \mathrm{C}$, a com tempo de permanência de $100 \mathrm{~s}$ foi escolhida por apresentar maior susceptibilidade à corrosão entre as as amostras da mesma faixa de temperatura. $\mathrm{O}$ objetivo nesta analisar, era verificar presença de carbonetos ou fases que pudessem aumentar ou reduzir a susceptiblidade à corrosão comparando com a aumento do tamanho médio dos grãos. De acordo com a Figura 11, a presença de carbonetos identificados no espectrograma da amostra com $1200^{\circ} \mathrm{C}$ a 100 s pode está relacionado à sua maior susceptibilidade à corrosão (Figura 11-b), haja vista que a presença de carbonetos de cromo é fator importante para tal mecanismo [13, $18]$. 


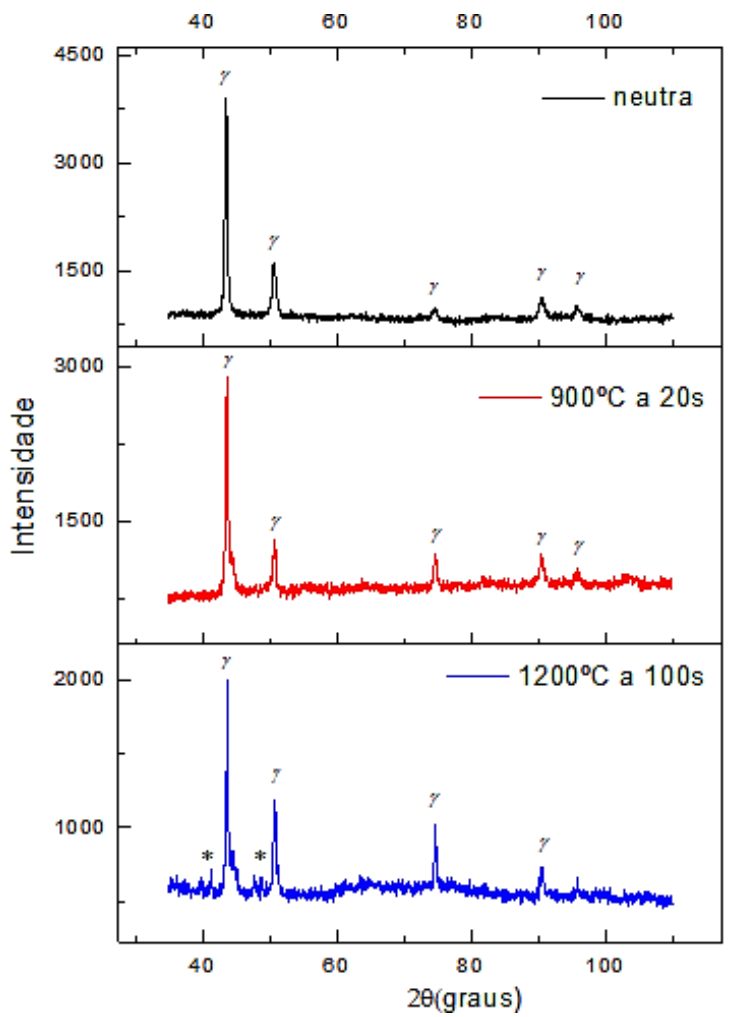

(a)

(b)

Figura 11: Amostras submetidas à difração de raios-x: (a) amostra neutra; (b) $900^{\circ} \mathrm{C}$ a $20 \mathrm{~s} \mathrm{e}$; (c) $1200^{\circ} \mathrm{C}$ a $100 \mathrm{~s}$ onde $(\gamma)$ austenita e (*) carboneto de cromo

Por outro lado, na análise da condição de $900{ }^{\circ} \mathrm{C}$ a $20 \mathrm{~s}$, obtiveram apenas a matriz austeníta identificada no espectrograma sem presença de carbonetos, evidenciando que a estrutura austenítica do material favorece uma maior resistência à corrosão [7, 2, 15], devido à influência de seus elementos de liga como o Mo [15] e da relação $\mathrm{Cr}_{\text {eq }} / \mathrm{Ni}_{\text {eq }}$ por estabilizar essa matriz [7,19]. Ainda de acordo com a Figura 11, foi possível observar que o aumento da temperatura ocasionou uma diminuição na intensidade no espectrograma da fase austenítica.

\section{CONCLUSÕES}

Durante a elaboração deste trabalho foi avaliado a susceptibilidade à corrosão das amostras simuladas em uma Gleeble com diferentes temperaturas de pico e tempos de permanência. De acordo com as análises realizadas, chegou-se às seguintes conclusões:

- Ao avaliar o aço AISI 316L submetido a uma simulação térmica por microscopia óptica, foi constatado que o aumento da temperatura e do tempo de permanência consequentemente aumentam o tamanho médio dos grãos;

- Através de um potenciostato foi possível analisar o potencial de corrosão de cada amostra simulada, onde as amostras submetidas a $900{ }^{\circ} \mathrm{C}-20 \mathrm{~s}$ e $1200{ }^{\circ} \mathrm{C}-0 \mathrm{~s}$ obtiveram os maiores potenciais de corrosão dentre todas as outras. Porém, as amostras submetidas a $1200{ }^{\circ} \mathrm{C}$ apresentaram um maior potencial de corrosão em relação às amostras submetidas a $900^{\circ} \mathrm{C}$, exceto para $1200^{\circ} \mathrm{C}-20 \mathrm{~s}$. Contudo, era esperado que a amostra $1200^{\circ} \mathrm{C}-100 \mathrm{~s}$ obtivesse um maior potencial e isso pode estar relacionado à não homogeneização da estrutura nesta condição;

- Utilizando o microscópio óptico nas amostras submetidas ao ensaio potenciodinâmico, foi notadamente observada a corrosão por pite no AISI 316L;

- Utilizando a técnica de difração de raios-x (DRX), foi possível observar a presença de carbonetos na amostra de maior temperatura e maior tempo de permanência $\left(1200{ }^{\circ} \mathrm{C}-100 \mathrm{~s}\right)$ que pode ter influenciado em sua susceptibilidade à corrosão, visto que para outras condições (amostra neutra e $900{ }^{\circ} \mathrm{C}-20 \mathrm{~s}$ ) foi possível observar apenas uma matriz austenítica $(\gamma)$. Além disso, a intensidade da fase austenítica diminui com o aumento da temperatura. 


\section{AGRADECIMENTOS}

Os autores gostariam de agradecer ao IFMA pelo suporte da infraestrutura, à CAPES pela bolsa de pósgraduação para um dos autores, e aos demais envolvidos que colaboraram indiretamente para este trabalho.

\section{BIBLIOGRAFIA}

[1] LLEWELLYN, D.T., Steels: Metallurgy \& Applications, 2 ed., Swansea, Butterworth-Heinemann, 1994.

[2] NUNES, L.P., Fundamentos de resistência à corrosão, 1 ed., Rio de Janeiro, Interciência, 2007.

[3] WOLYNEC, S., Técnicas Eletroquímicas em Corrosão, 1 ed., São Paulo, EDUSP, 2013.

[4] BERTON, E. M., Efeito das temperaturas de têmpera e de revenido na resistência à corrosão da camada martensítica de alto nitrogênio produzida por SHTPN sobre o aço AISI 409, Tese de M. Sc., UTFPR, Curitiba, PR, Brasil, 2014.

[5] DIAS, J.C.N., OLIVEIRA, R.C.B.C.A.N., ABREU, H.F.G.S., et al., "Estudo da Ocorrência da Corrosão em Aços Inoxidáveis AISI 316L e 444 Utilizados na Indústria Petroquímica", In: $22^{\circ}$ CONBRASCORR Congresso Brasileiro de Corrosão, Salvador, Bahia, Brasil, 19-21 Agosto 2002.

[6] SILVA, C.C., JÚNIOR, J.M.B.R., MACHADO, J.P.S.E., et al., "Estudo da Corrosão na ZAC do Aço Inoxidável Austenítico AISI 316L Causada por Petróleo Pesado da Bacia de Campos", In: $3^{\circ}$ Congresso Brasileiro de P\&D em Petróleo e Gás, Salvador, Bahia, Brasil, 02-05 Outubro 2005.

[7] KIANERSI, D., MOSTAFAEI, A., AMADEH, A.A., "Resistance spot welding joints of AISI 316L austenitic stainless steel sheets: Phase transformations, mechanical properties and microstructure characterizations", Materials and Design, v. 61, pp. 251-263, Sep. 2014.

[8] ÖZYÜREK, D., "An effect of weld current and weld atmosphere on the resistance spot weldability of 304L austenitic stainless steel”, Materials and Design, v. 29, n. 3, pp. 597-603, Mar. 2007.

[9] KOCABEKIR, B., KAÇAR, R., GÜNDÜZ, S., et al., "An effect of heat input, weld atmosphere and weld cooling conditions on the resistance spot weldability of 316L austenitic stainless steel", Journal of Materials Processing Technology, v. 195, n.1-3, pp. 327-335, Jan. 2008.

[10] LI, S.X., HE, Y.N., YU, S.R., et al., "Evaluation of the effect of grain size on chromium carbide precipitation and intergranular corrosion of 316L stainless steel", Corrosion Science, v. 66, pp. 211-216, Jan. 2013.

[11] WILLIAMS, J.G., BARBARO, F.J., "Susceptibility and Prevention of Weld HAZ Sensitisation and Intergranular Stress Corrosion Cracking in Various 12\% Cr Steels", Iron and Steel Technology Conference, pp. 605-618, Charlotte, NC, USA, 09-12 May 2005.

[12] CHATURVEDI, M.C., JENA, A.K., "The hole of alloying elements in the design of nickel-base superalloys", Journal of Materials Science, v. 19, n. 10, pp. 3121-3139, Nov. 1983.

[13] GARCIA, C., TIEDRA, M.P., BLANCO, Y., et al., "Intergranular corrosion of welded joints of austenitic stainless steels studied by using an electrochemical minicell", Corrosion Science, v. 50, n. 08, pp. 23922397, Aug. 2008.

[14] GUILHERME, H., KURI, S.E., ROVERE, C.A.D., et al., "Resistência à corrosão da junta dissimilar soldada pelo processo TIG composta pelos aços inoxidáveis AISI 316L e AISI 444", Soldagem e Inspeção, v. 19, n. 1, p. 042-050, Mar. 2014.

[15] LUZ, T.S., FARIAS, J.P., NETO, P.L., "O uso da polarização eletroquímica de reativação potenciocinética cíclica (PERPC) na avaliação da sensitização de aços inoxidáveis submetidos à soldagem", Soldagem e Inspeção, v. 10, n. 3, Jul/Set 2005.

[16] GUO, Y., SUN, T., HU, J., et al., "Microstructure evolution and pitting corrosion resistance of the Gleeble-simulated heat-affected zone of a newly developed lean duplex stainless steel 2002", Journal of Alloys and Compounds, v. 658, n. 15, pp. 1031-1040, Feb. 2016.

[17] RAMÍREZ, M.F.G., Influência da microestrutura nas propriedades mecânicas e na fragilização por hidrogênio em um aço microligado, Tese de D. Sc., Escola politécnica da Universidade de São Paulo, São Paulo, SP, Brasil, 2012.

[18] DADFAR, M., FATHI, M.H., KARIMZADEH, F., et al., "Effect of TIG welding on corrosion behavior of 316L stainless steel", Materials Letters, v. 61, n. 11-12, pp. 2343-2346, May 2007.

[19] SCHVARTZMAN, M.M.A.M., QUINAN, M.A.D., CAMPOS, W.R.C., et al., "Avaliação da Suscetibilidade à Corrosão sob Tensão da ZAC do aço inoxidável AISI 316L em Ambiente de Reator Nuclear PWR", Soldagem e Inspeção, v. 14, n. 3, p. 228-237, Jul/Sep 2009. 
[20] ZHENG, H., YE, X., JIANG, L., et al., "Study on microstructure of low carbon 12\% chromium stainless steel in high temperature heat-affected zone", Materials and Design, v. 31, n.10, pp. 4836-4841, Dec. 2010.

[21] VILARINHO, O.L., ARAÚJO, D.B., "Metodologia de Baixo Custo para Levantamento de Diagramas CCT em Soldagem”, Soldagem e Inspeção, v. 15, n. 3, pp. 184-190, Jul/Set 2010.

[22] LI, S.X., Li, L., Yu S.R., et al., "Investigation of intergranular corrosion of 316L stainless steel diffusion bonded joint by electrochemical potentiokinetic reactivation”, Corrosion Science, v. 53, n. 1, pp. 99-104, Jan. 2011.

[23] ASTM E 407-99. Standard Practice for Microetching Metals and Alloys.

[24] PINTO, L. C. M. "Quantikov um analisador microestrutural para o ambiente windows”. Tese de D. IPEN - Instituo de Pesquisas Energéticas e Nucleares, São Paulo, SP, Brasil, 1996.

[25] ASTM E112. Standard Test Methods for Determining Average Grain Size.

[26] AMARAL, T. S., CARBONI, M. C., SCOTTI, A. “Avaliação da Aplicação de um Atlas de Soldagem de um Aço Bainítico Microligado ao Nióbio”, Soldagem \& Inspeção, v. 22, n. 2, p. 163-173, Jun/2017.

[27] SILVA, R. F. "Caracterização da zona termicamente afetada de aço produzido via resfriamento acelerado", Dissertação de Mestrado, UFMG - Universidade Federal de Minas Gerais, Belho Horizonte, MG, Brasil, 2010.

[28] MEI, P. R., SILVA. “Aços e ligas especiais”, Sumaré, SP, Eletrometal Metais Especiais, 1987.

\section{ORCID}

Thiago Aguiar Santos

Renato Conde dos Santos

Carmem Célia Francisco do Nascimento

Waldemir dos Passos Martins https://orcid.org/0000-0002-0687-3342

https://orcid.org/0000-0002-1350-1133

https://orcid.org/0000-0002-3918-0366

https://orcid.org/0000-0003-1945-1429 